\title{
Three-Component Copper-Phosphonate-Auxiliary Ligand Systems: Proton Conductors and Efficient Catalysts in Mild Oxidative Functionalization of Cycloalkanes
}

\author{
Eirini Armakola, ${ }^{\dagger}$ Rosario M. P. Colodrero, ${ }^{\S}$ Montse Bazaga-García, ${ }^{\ddagger}$ Inés R. Salcedo, ${ }^{\ddagger}$
} Duane Choquesillo-Lazarte, ${ }^{\Perp \odot}$ Aurelio Cabeza, ${ }^{\ddagger}{ }^{\circledR}$ Marina V. Kirillova, ${ }^{\perp}$ Alexander M. Kirillov, ${ }^{*},{ }^{\prime}, \#_{\odot}$ and Konstantinos D. Demadis* $* \dagger$

\begin{abstract}
${ }^{\dagger}$ Crystal Engineering, Growth and Design Laboratory, Department of Chemistry, University of Crete, Voutes Campus, Crete, GR-71003, Greece

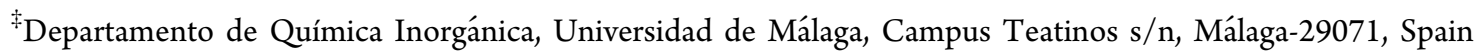

${ }^{\S}$ Faculty of Science and Engineering, University of Wolverhampton, Wulfruna Street, Wolverhampton, WV1 1LY, United Kingdom

"Laboratorio de Estudios Cristalográficos, IACT, CSIC-Universidad de Granada, Granada-18100, Spain

${ }^{\perp}$ Centro de Química Estrutural, Instituto Superior Técnico, Universidade de Lisboa, Av. Rovisco Pais, 1049-001, Lisbon, Portugal

\#Peoples' Friendship University of Russia (RUDN University), 6 Miklukho-Maklay st., Moscow, 117198, Russian Federation
\end{abstract}

Supporting Information

ABSTRACT: The synthesis, structural characterization, topological analysis, proton conductivity, and catalytic properties are reported of two $\mathrm{Cu}(\mathrm{II})$-based compounds, namely a dinuclear $\mathrm{Cu}(\mathrm{II})$ complex $\left[\mathrm{Cu}_{2}(\mu \text {-VPA })_{2}(\text { phen })_{2}\left(\mathrm{H}_{2} \mathrm{O}\right)_{2}\right]$. $8 \mathrm{H}_{2} \mathrm{O}(1)\left(\mathrm{H}_{2} \mathrm{VPA}=\right.$ vinylphosphonic acid, phen $=1,10-$ phenanthroline) and a $1 \mathrm{D}$ coordination polymer $[\mathrm{Cu}(\mu$ $\left.\mathrm{SO}_{4}\right)($ phen $\left.)\left(\mathrm{H}_{2} \mathrm{O}\right)_{2}\right]_{\infty}(2)$. Their structural features and $\mathrm{H}$ bonding interactions were investigated in detail, showing that the metal-organic structures of $\mathbf{1}$ and $\mathbf{2}$ are extended by multiple hydrogen bonds to more complex $2 \mathrm{D}$ or $1 \mathrm{D} \mathrm{H}$ bonded architectures with the kgd [Shubnikov plane net

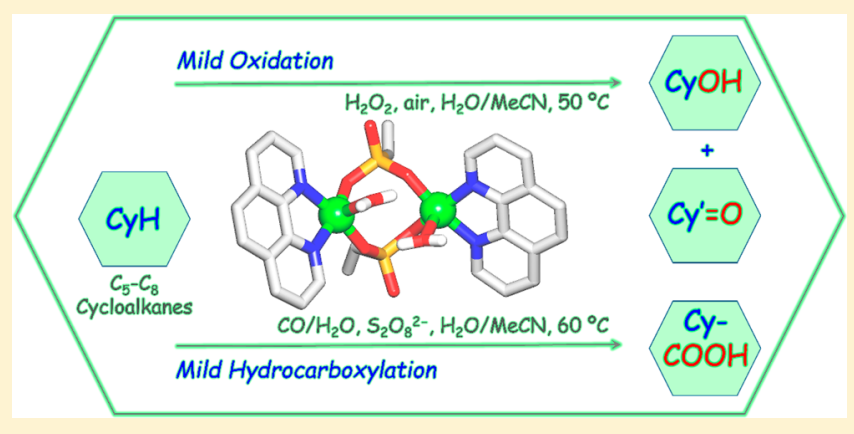
(3.6.3.6)/dual] and SP 1-periodic net $(4,4)(0,2)$ topology, respectively. These nets are primarily driven by the $\mathrm{H}$-bonding interactions involving water ligands and $\mathrm{H}_{2} \mathrm{O}$ molecules of crystallization; besides, the $\left(\mathrm{H}_{2} \mathrm{O}\right)_{4} /\left(\mathrm{H}_{2} \mathrm{O}\right)_{5}$ clusters were identified in $\mathbf{1}$. Both $\mathbf{1}$ and $\mathbf{2}$ are moderate proton conductors, with proton conductivity values, $\sigma=3.65 \times 10^{-6}$ and $3.94 \times 10^{-6} \mathrm{~S} \cdot \mathrm{cm}^{-1}$, respectively (measured at $80{ }^{\circ} \mathrm{C}$ and $95 \%$ relative humidity). Compounds 1 and 2 are also efficient homogeneous catalysts for the mild oxidative functionalization of $\mathrm{C}_{5}-\mathrm{C}_{8}$ cycloalkanes (cyclopentane, cyclohexane, cycloheptane, and cyclooctane), namely for the oxidation by $\mathrm{H}_{2} \mathrm{O}_{2}$ to give cyclic alcohols and ketones and the hydrocarboxylation by $\mathrm{CO} / \mathrm{H}_{2} \mathrm{O}$ and $\mathrm{S}_{2} \mathrm{O}_{8}{ }^{2-}$ to the corresponding cycloalkanecarboxylic acids as major products. The catalytic reactions proceed under mild conditions $\left(50-60{ }^{\circ} \mathrm{C}\right)$ in aqueous acetonitrile medium, resulting in up to $34 \%$ product yields based on cycloalkane substrate.

\section{INTRODUCTION}

Metal phosphonates have attracted the interest of coordination chemists during the last decades. There is a plethora of reasons. (a) Phosphonate ligands display different coordination modes and can bridge several metal binding sites, thus yielding a phalanx of architectures. ${ }^{1}$ (b) Phosphonic acids (and their deprotonated forms) can coordinate virtually to any metal ion from the Periodic Table. ${ }^{2-6}$ (c) Their sensitivity to $\mathrm{pH}$ offers the opportunity to perform syntheses in a wide spectrum of $\mathrm{pH}$ values, with different results. ${ }^{7,8}$ (d) The "metal/phosphonate" system can accommodate other auxiliary ligands (such as N-heterocycles), thus altering the dimensionality and architecture of the resulting product. $^{9-11}$ (e) Metal phosphonate coordination polymers or complexes are usually stable and robust. ${ }^{12}$ Their stability is one of the reasons for their increasing use in catalysis.

Currently, synthetic efforts in metal phosphonate chemistry have been devoted to including a secondary auxiliary ligand (SAL). ${ }^{13}$ Such ligands are usually neutral polypyridines, ${ }^{14}$ although other anionic ligands (such as carboxylates) have also been utilized. ${ }^{15}$ Incorporation of a SAL can induce profound changes in the final product, such as a change in dimensionality, creation of hydrophobic domains, changes in the coordination mode of the metal centers, and, in certain cases, rupture of the "coordination polymer" architecture. In

Received: May 14, 2018

Published: August 13, 2018 
the case of copper-based materials several examples have been reported. Representative examples include the following. A 3D bimetallic copper vanadium phosphonate framework can be isolated from the $\mathrm{Cu} / \mathrm{V} /$ terpyridine/methane tetra-p-phenylphosphonic acid system. ${ }^{16}$ Low-dimensional $\mathrm{Cu}(\mathrm{II})$-based organophosphonates can be prepared from the $\mathrm{Cu} / 2,2^{\prime}$-bpy/ anthracenephosphonate system. ${ }^{17}$ Various structural motifs have been observed in compounds produced from the combination of $\mathrm{Cu}(\mathrm{II})$ with 1,3,5-benzenetriphosphonic acid and $\mathrm{N}$-donor ligands such as pyrazine, 1,2-bis(4-pyridyl)ethylene, and 1,3-bis(4-pyridyl)propane. ${ }^{18}$ Reaction of $\mathrm{Cu}(\mathrm{II})$ with 1-hydroxyethylidenediphosphonate and 2,2'-bipyridine afforded a $1 \mathrm{D}$ coordination polymer. ${ }^{19}$ A zigzag 1D coordination polymer has been structurally characterized that contains $\mathrm{Cu}$ (II)-phenanthroline nodes and 1,2-ethylenediphosphate. ${ }^{20}$ Further useful information can be found in a recent review. $^{21}$

Metal phosphonate compounds have recently entered the arena of catalytic transformations. ${ }^{22}$ Some representative catalytic transformations using metal phosphonates as catalysts include $\mathrm{CO}_{2}$ coupling with epoxides to give cyclic carbonates, ${ }^{23}$ selective liquid phase oxidation of cyclohexanone to adipic acid, ${ }^{24}$ hydrogen evolution, ${ }^{25}$ heterogeneous water oxidation, ${ }^{26}$ alcoholysis of styrene oxide, acetalization of benzaldehyde and cyclohexanaldehyde, and ketalization of cyclohexanone, ${ }^{27}$ oxidation of thioethers, ${ }^{28}$ conversion of ethyl levulinate to $\gamma$-valerolactone, ${ }^{29}$ heterogeneous asymmetric allylboration, propargylation, Friedel-Crafts alkylation and sulfoxidation reactions, ${ }^{30}$ photocatalytic water-splitting $\mathrm{H}_{2}$ evolution, ${ }^{31}$ and cyanosilylation of aldehydes and ring opening of meso-carboxylic anhydrides. ${ }^{32}$

Among various types of organic substrates for catalytic transformations, alkanes are particularly important given their high inertness and natural abundance as hydrocarbon feedstocks. ${ }^{33,34}$ Hence, the search for new catalytic systems and reaction protocols capable of transforming alkanes into valueadded products represents an important research direction in modern chemistry. ${ }^{33,34}$ Particular attention is focused on the design of low-cost transition metal catalysts for the oxidative functionalization of alkanes under mild conditions. Given the presence of copper in the active sites of various oxidation enzymes (e.g., particulate methane monooxygenase, multicopper oxidases) along with its rich coordination chemistry and recognized application in oxidation catalysis, ${ }^{35,36}$ the synthesis and exploration of novel catalysts based on copper complexes or coordination polymers are particularly attractive. An interesting idea also concerns the design of catalytically active copper cores that would combine versatile and relatively labile phosphonate ligands with strong chelating $\mathrm{N}, \mathrm{N}$-donors, thus resulting in a three component (Cu-phosphonate-auxiliary ligand) system.

Aiming at exploring a catalytic potential of such multicomponent copper cores and following our general interest in the mild oxidative functionalization of alkanes, ${ }^{37-39}$ the present paper reports the synthesis, full characterization, proton conductivity, and structural and topological features, as well as oxidation catalytic activity of a novel dinuclear $\mathrm{Cu}(\mathrm{II})$ compound $\left.\left[\mathrm{Cu}_{2}(\mu \text {-VPA })_{2} \text { (phen }\right)_{2}\left(\mathrm{H}_{2} \mathrm{O}\right)_{2}\right] \cdot 8 \mathrm{H}_{2} \mathrm{O}(\mathbf{1})\left(\mathrm{H}_{2} \mathrm{VPA}\right.$ $=$ vinylphosphonic acid, phen $=1,10$-phenanthroline). For comparative purposes, the properties and catalytic behavior of a structurally related $1 \mathrm{D}$ coordination polymer $[\mathrm{Cu}(\mu$ $\left.\mathrm{SO}_{4}\right)($ phen $\left.)\left(\mathrm{H}_{2} \mathrm{O}\right)_{2}\right]_{\infty}$ (2, byproduct in the synthesis of $\left.\mathbf{1}\right)^{40}$ wherein a $\mu$-VPA block is substituted by a $\mu$-sulfate ligand have also been evaluated. Both $\mathbf{1}$ and $\mathbf{2}$ act as efficient homogeneous catalysts for the mild oxidative functionalization of $\mathrm{C}_{5}-\mathrm{C}_{8}$ alkanes to the corresponding cyclic alcohols and ketones (oxidation) or cyclalkanecarboxylic acids (hydrocarboxylation).

\section{EXPERIMENTAL SECTION}

Reagents and Equipment. All chemicals (copper salts, ligands, cycloalkanes, and solvents) were purchased commercially and were used as received without further purification. Ion exchange columndeionized (DI) water was used for the syntheses. Stock aqueous solutions of $\mathrm{NaOH}$ and $\mathrm{HCl}(1.0$ and $0.1 \mathrm{M})$ were used for $\mathrm{pH}$ adjustment during the synthesis. In catalytic oxidation and hydrocarboxylation of cycloalkanes, gas chromatography (GC) analyses of the reaction mixtures were run on an Agilent Technologies 7820A series gas chromatograph ( $\mathrm{He}$ as carrier gas) equipped with the FID detector and BP20/SGE $(30 \mathrm{~m} \times 0.22 \mathrm{~mm} \times 0.25 \mu \mathrm{m})$ capillary column.

Syntheses. $\left[\mathrm{Cu}_{2}(\mu \text {-VPA })_{2}(\text { phen })_{2}\left(\mathrm{H}_{2} \mathrm{O}\right)_{2}\right] \cdot 8 \mathrm{H}_{2} \mathrm{O}$ (1). A quantity of $\mathrm{H}_{2} \mathrm{VPA}(9 \mu \mathrm{L}$ of a $90 \%$ aqueous solution, $0.10 \mathrm{mmol}$ ) was dissolved in $10 \mathrm{~mL}$ of DI water. Equimolar quantities of phen $(0.020 \mathrm{~g}, 0.10$ $\mathrm{mmol})$ and $\mathrm{CuSO}_{4} \cdot 5 \mathrm{H}_{2} \mathrm{O}(0.025 \mathrm{~g}, 0.10 \mathrm{mmol})$ were added to the above solution under rigorous stirring. The $\mathrm{pH}$ was adjusted to 6.8 with $\mathrm{HCl}$ and $\mathrm{NaOH}$ stock solutions. The resulting blue solution was left undisturbed for $\sim 7$ days at room temperature. Blue crystals were formed due to solvent evaporation (final $\mathrm{pH}=6.71$ ) and were isolated by filtration, washed with small amounts of DI water, and airdried. The yield was $74 \%$ based on the metal salt. Elemental analysis for the formula $\left\{\left[\mathrm{Cu}\left(\mathrm{C}_{12} \mathrm{H}_{8} \mathrm{~N}_{2}\right)\left(\mathrm{C}_{2} \mathrm{H}_{3} \mathrm{O}_{3} \mathrm{P}\right)\left(\mathrm{H}_{2} \mathrm{O}\right)\right] \cdot 4 \mathrm{H}_{2} \mathrm{O}\right\}_{2}(\mathrm{MW}=$ $879.67 \mathrm{~g} / \mathrm{mol}$ ): Calculated C $38.23 \%, \mathrm{H} 4.81 \%$, N 6.37\%. Found C $37.93 \%, \mathrm{H} 4.96 \%$, N 6.46\%.

$\left[\mathrm{Cu}\left(\mu-\mathrm{SO}_{4}\right)(\text { phen })\left(\mathrm{H}_{2} \mathrm{O}\right)_{2}\right]_{\infty}$ (2). Identical procedures and quantities as for compound $\mathbf{1}$ were followed, with the exception that the synthesis $\mathrm{pH}$ was 3.6 (final $\mathrm{pH}=3.44$ ). The yield was $68 \%$ based on the metal salt. Elemental analysis for the formula $[\mathrm{Cu}-$ $\left.\left(\mathrm{H}_{2} \mathrm{O}\right)_{2}\left(\mathrm{C}_{12} \mathrm{H}_{8} \mathrm{~N}_{2}\right)\right]\left[\left(\mathrm{SO}_{4}\right)\right](\mathrm{MW}=375.84 \mathrm{~g} / \mathrm{mol})$ : Calculated $\mathrm{C}$ $38.40 \%$, H 3.23\%, N 7.47\%. Found: C $37.90 \%$, H 3.19\%, N 7.49\%.

Instrumentation. Thermogravimetric Analysis (TGA). Thermogravimetric analysis (TGA) data were recorded on an SDT-Q600 analyzer from TA Instruments. The temperature varied from RT to $900{ }^{\circ} \mathrm{C}$ at a heating rate of $10^{\circ} \mathrm{C} \cdot \mathrm{min}^{-1}$. Measurements were carried out on samples in open platinum crucibles under a flow of air.

Single Crystal X-ray Determination. Crystals were handled under inert conditions and immersed in perfluoropolyether as protecting oil for manipulation. Suitable crystals of $\mathbf{1}$ were mounted on MiTeGen Micromounts, and these samples were used for data collection. Data were collected on a Bruker D8 Venture diffractometer. The data were processed with an APEX2 program $^{41}$ and corrected for absorption using SADABS. ${ }^{42}$ The structures were solved by direct methods, which revealed the position of all non-hydrogen atoms. ${ }^{43}$ These atoms were refined on $\mathrm{F}^{2}$ by a full-matrix least-squares procedure using anisotropic displacement parameters. All hydrogen atoms were located in difference Fourier maps and included as fixed contributions riding on attached atoms with isotropic thermal displacement parameters $1.2(-\mathrm{C}-\mathrm{H})$ or $1.5(-\mathrm{O}-\mathrm{H})$ times those of the respective atom. Crystallographic data for $\mathbf{1}$ are reported in Table 1.

Topological Analysis. The H-bonded architectures in $\mathbf{1}$ and $\mathbf{2}$ were analyzed from the topological viewpoint by following the concept of the simplified underlying net. ${ }^{44-47}$ Such nets were generated by contracting (a) the $\left[\mathrm{Cu}_{2}(\mu \text {-VPA })_{2}(\text { phen })_{2}\left(\mathrm{H}_{2} \mathrm{O}\right)_{2}\right]$ molecular units and $\left(\mathrm{H}_{2} \mathrm{O}\right)_{4}$ clusters in 1 or $(\mathrm{b})$ the $\left[\mathrm{Cu}(\text { phen })_{2}\left(\mathrm{H}_{2} \mathrm{O}\right)_{2}\right]^{2+}$ and $\mu$ $\mathrm{SO}_{4}{ }^{2-}$ moieties in 2 to the corresponding centroids, maintaining their connectivity via hydrogen bonds. Only strong $\mathrm{D}-\mathrm{H} \cdots \mathrm{A}$ hydrogen bonds were considered, wherein the $\mathrm{H} \cdots \mathrm{A}<2.50 \AA$, $\mathrm{D} \cdots \mathrm{A}<3.50 \AA$, and $\angle(\mathrm{D}-\mathrm{H} \cdots \mathrm{A})>120^{\circ}$; D and $\mathrm{A}$ stand for donor and acceptor atoms. $^{44,45}$ Topological classification of the obtained underlying nets was performed.

Powder X-ray Diffraction. Laboratory X-ray powder diffraction (XRPD) patterns were collected on a PANanalytical EMPYREAN 
Table 1. Selected Crystallographic Data for $\mathrm{Cu}_{2}(\mathrm{phen})_{2}(\mu$ $\mathrm{VPA})_{2}\left(\mathrm{H}_{2} \mathrm{O}\right)_{2} \cdot 8 \mathrm{H}_{2} \mathrm{O}(\mathbf{1})$

\begin{tabular}{|c|c|}
\hline Compound & 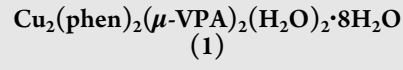 \\
\hline Empirical formula & $\mathrm{C}_{28} \mathrm{H}_{42} \mathrm{Cu}_{2} \mathrm{~N}_{4} \mathrm{O}_{16} \mathrm{P}_{2}$ \\
\hline F.W. $\left(\mathrm{g} \mathrm{mol}^{-1}\right)$ & 879.67 \\
\hline Temperature & $100 \mathrm{~K}$ \\
\hline Space group & $\mathrm{C} 2 / \mathrm{c}$ \\
\hline$\lambda(\AA)$ & 0.71073 \\
\hline$a(\AA)$ & $27.720(8)$ \\
\hline$b(\AA)$ & $8.091(2)$ \\
\hline$c(\AA)$ & $20.036(7)$ \\
\hline$\alpha(\operatorname{deg})$ & 90.0 \\
\hline$\beta(\operatorname{deg})$ & $127.944(9)$ \\
\hline$\gamma(\operatorname{deg})$ & 90.0 \\
\hline$V\left(\AA^{3}\right)$ & $3544(2)$ \\
\hline Crystal size $(\mathrm{mm})$ & $0.12 \times 0.08 \times 0.06$ \\
\hline$Z$ & 8 \\
\hline$\rho_{\text {calc }}\left(\mathrm{g} \cdot \mathrm{cm}^{-3}\right)$ & 1.649 \\
\hline $2 \theta$ range $(\mathrm{deg})$ & $2.578-27.618$ \\
\hline Data/Restraints/Parameters & $4087 / 0 / 244$ \\
\hline No. reflections & 15998 \\
\hline Independent reflections $[I>2 \sigma(I)]$ & 4087 \\
\hline GoF, $F^{2}$ & 1.014 \\
\hline $\mathrm{R}$ Factor $[I>2 \sigma(I)]$ & $\mathrm{R} 1^{a}=0.0393, \mathrm{wR}^{a}=0.0876$ \\
\hline R Factor (all data) & $\mathrm{R} 1^{a}=0.0585, \mathrm{wR} 2^{a}=0.0956$ \\
\hline CCDC Reference Code & 1837061 \\
\hline
\end{tabular}

diffractometer, in the Bragg-Brentano reflection configuration by using $\mathrm{Cu} \mathrm{K}_{\alpha 1,2}$ radiation and a PIXcel detector. X-ray patterns were recorded between 4 and $70^{\circ}(2 \theta)$, with a $0.026^{\circ}$ step size and an equivalent counting time of $\sim 24 \mathrm{~s} / \mathrm{step}$. Thermodiffractometric studies were carried using an Anton Paar TTK450 Camera under static air. Data were collected at different temperatures up to $200{ }^{\circ} \mathrm{C}$ with a delay time of $15 \mathrm{~min}$ to ensure thermal stabilization. XRPD patterns were recorded between 4 and $50^{\circ}$ in $2 \theta$, with a step size of $0.013^{\circ}$ and an equivalent counting time of $\sim 150 \mathrm{~s} / \mathrm{step}$.

Proton Conductivity. Impedance measurements were carried out on cylindrical pellets (diameter $\sim 5 \mathrm{~mm}$ and thickness $\sim 1 \mathrm{~mm}$ ) obtained by pressing $40 \mathrm{mg}$ of sample at $250 \mathrm{MPa}$, for $1 \mathrm{~min}$. The pellets were pressed between porous C electrodes (Sigracet, GDL 10 $\mathrm{BB}$, no $\mathrm{Pt}$ ). The sample cell was placed inside a temperature- and humidity-controlled chamber (Espec SH-222). AC impedance data were collected using an AUTOLAB PGSTAT302N analyzer over the frequency range from $20 \mathrm{~Hz}$ to $10^{5} \mathrm{~Hz}$ with an applied voltage of 0.35 V. To equilibrate water content, pellets were first preheated $\left(0.2^{\circ} \mathrm{C} /\right.$ min) from 25 to $80{ }^{\circ} \mathrm{C}$ and $95 \% \mathrm{RH}$. Impedance spectra were recorded on cooling using a stabilization time of $3 \mathrm{~h}$ for each temperature $\left(80,60,40,25^{\circ} \mathrm{C}\right)$. Water condensation on sample was avoided by reducing first the relative humidity before decreasing temperature. All measurements were electronically controlled by the NOVA 2.1 package of programs.

Mild Oxidation of Cycloalkanes. The oxidation reactions of cycloalkanes were performed in air atmosphere in a thermostated glass reactor system equipped with a condenser, under vigorous stirring at $50{ }^{\circ} \mathrm{C}$ and using $\mathrm{MeCN}$ as solvent (up to $5 \mathrm{~mL}$ total volume). In a typical experiment, copper catalyst $(0.01 \mathrm{mmol})$ and gas chromatography (GC) internal standard $\left(\mathrm{MeNO}_{2}, 50 \mu \mathrm{L}\right)$ were introduced into $\mathrm{MeCN}$ solution, followed by the addition of a cycloalkane substrate $(2 \mathrm{mmol})$. The reaction started upon addition of hydrogen peroxide $\left(50 \%\right.$ in $\left.\mathrm{H}_{2} \mathrm{O}, 10 \mathrm{mmol}\right)$ in one portion. The oxidation reactions were monitored by withdrawing small aliquots after different periods of time; these were treated with $\mathrm{PPh}_{3}$ for the reduction of remaining $\mathrm{H}_{2} \mathrm{O}_{2}$ and cycloalkyl hydroperoxides ${ }^{48,49}$ that are typically formed as primary products in cycloalkane oxidations.
The samples were then analyzed by GC using nitromethane as an internal standard. Attribution of peaks was made by comparison with chromatograms of authentic samples.

Hydrocarboxylation of Cycloalkanes. In a typical experiment, the reaction mixtures were prepared as follows: a stainless steel autoclave $(20.0 \mathrm{~mL})$ equipped with a Teflon-coated magnetic stirring bar was filled with copper catalyst $(0.01 \mathrm{mmol}), \mathrm{K}_{2} \mathrm{~S}_{2} \mathrm{O}_{8}(1.5 \mathrm{mmol}), \mathrm{H}_{2} \mathrm{O}$ $(2.0 \mathrm{~mL})$ and $\mathrm{MeCN}(4.0 \mathrm{~mL}$; total solvent volume was $6.0 \mathrm{~mL})$, and cycloalkane $(1.0 \mathrm{mmol})$. Then, the autoclave was closed and flushed with $\mathrm{CO}$ three times to remove the air, and finally pressurized with 20 atm of CO. CAUTION: Due to the toxicity of CO, all operations should be carried out in a well-ventilated hood! The obtained reaction mixture was stirred for $3 \mathrm{~h}$ at $60{ }^{\circ} \mathrm{C}$ using a magnetic stirrer and an oil bath, whereupon it was cooled in an ice bath, degassed, opened, and transferred to a flask with tap. Diethyl ether $(9.0 \mathrm{~mL})$ and cycloheptanone ( $45 \mu \mathrm{L}$, typical GC internal standard) were added. Cyclohexanone was used as a GC internal standard in cycloheptane hydrocarboxylation. The obtained mixture was vigorously stirred for 10 min using a magnetic stirrer. Then, the organic layer was analyzed by gas chromatography (internal standard method), revealing the formation of the corresponding cycloalkanecarboxylic acids as the dominant products. The formation of oxidation products (cyclic alcohols and ketones) was also detected. Attribution of peaks was made by comparison with chromatograms of authentic samples.

\section{RESULTS AND DISCUSSION}

Synthesis and Characterization of the Catalysts. Syntheses of the compounds $\left[\mathrm{Cu}_{2}(\mu \text {-VPA })_{2}(\mathrm{phen})_{2}\left(\mathrm{H}_{2} \mathrm{O}\right)_{2}\right]$. $8 \mathrm{H}_{2} \mathrm{O}(1)$ and $\left[\mathrm{Cu}\left(\mu-\mathrm{SO}_{4}\right)(\text { phen })\left(\mathrm{H}_{2} \mathrm{O}\right)_{2}\right]_{\infty}(2)$ were carried out in aqueous solutions under identical conditions, except the solution $\mathrm{pH}$ value (6.8 for $\mathbf{1}$ and 3.6 for $\mathbf{2}$ ). Products were isolated as crystalline solids that precipitated out of solution without addition of any secondary solvent.

The $\mathrm{p} K_{\mathrm{a}}$ values of the $\mathrm{H}_{2} \mathrm{VPA}$ ligand are 2.6 and 7.3. . $^{50,51}$ The synthesis of 1 was carried out at the $\mathrm{pH}$ value of 6.8; therefore, VPA should be at least monodeprotonated $\left(-\mathrm{PO}_{3} \mathrm{H}^{-}\right)$with a " -1 " charge and partially bis-deprotonated (based on the proximity of the $\mathrm{p} K_{\mathrm{a} 2}$ value and the synthesis $\mathrm{pH}$ ). The phosphonic group of VPA in the structure of $\mathbf{1}$ (vide infra) is completely deprotonated $\left(-\mathrm{PO}_{3}{ }^{2-}\right)$ carrying a " -2 " charge. Thus, the binuclear complex $\mathbf{1}$ is neutral. Such deprotonation behavior is not surprising in metal phosphonate chemistry. ${ }^{52}$ Hence, the following equation can be envisioned for the synthesis of the copper(II) dimer $\mathbf{1}$ :

$$
\begin{aligned}
& 2 \mathrm{CuSO}_{4} \cdot 5 \mathrm{H}_{2} \mathrm{O}+2 \mathrm{H}_{2} \mathrm{VPA}+2 \text { phen } \\
& \stackrel{\text { water }}{\longrightarrow}\left[\mathrm{Cu}_{2}(\mu-\mathrm{VPA})_{2}(\text { phen })_{2}\left(\mathrm{H}_{2} \mathrm{O}\right)_{2}\right] \cdot 8 \mathrm{H}_{2} \mathrm{O}(\mathbf{1}) \\
& \quad+2 \mathrm{H}_{2} \mathrm{O}+\mathrm{H}_{2} \mathrm{SO}_{4}
\end{aligned}
$$

Decrease in the $\mathrm{pH}$ value to 3.6 during synthesis affords a related product 2, which does not contain $\mu$-VPA, but instead a bridging sulfate (originating from the copper(II) sulfate). In contrast to 1 , compound 2 is a $1 \mathrm{D}$ coordination polymer containing $\mathrm{Cu}^{2+}$ centers in an octahedral arrangement, coordinated by the two $\mathrm{N}$ atoms of the chelating phen ligand, two water molecules in a cis configuration, and two oxygen atoms (from the bridging sulfate) in a trans configuration. The synthesis of $\mathbf{2}$ can be rationalized based on the fact that the sulfate dianion is a stronger ligand for $\mathrm{Cu}^{2+}$ at $\mathrm{pH}$ 3.6, effectively competing with the monoanionic $\mathrm{HVPA}^{-}$ligand. Furthermore, formation of $\mathbf{2}$ is driven by the hydrogen bonding interactions developed between the $1 \mathrm{D}$ chains (see structural description below). The following equation can be envisioned for the synthesis of $\mathbf{2}$ : 

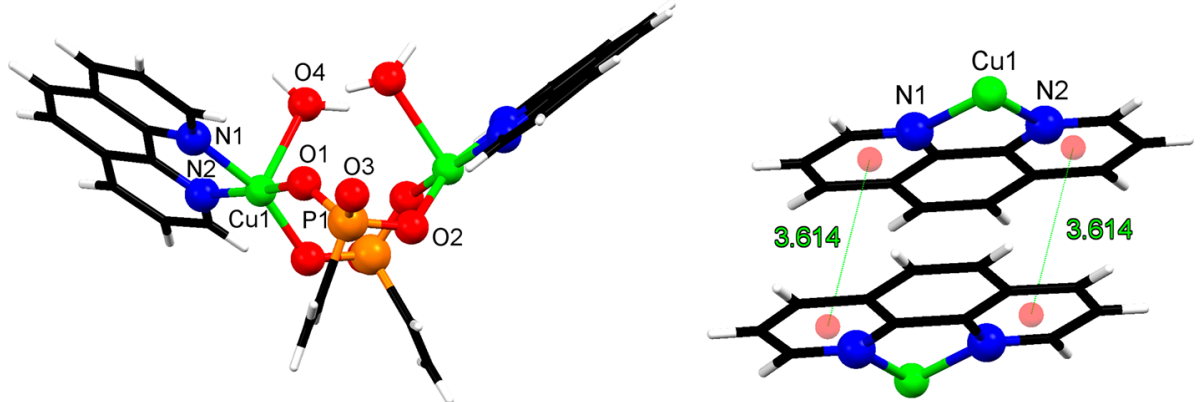

Figure 1. Left: Structure of the binuclear unit in $\mathbf{1}$, showing the coordination environment of the $\mathrm{Cu}^{2+}$ centers, with numbering of the essential atoms. Right: $\pi-\pi$ interactions between the phen pyridyl rings in 1 . VPA and water ligands are omitted for clarity.

$$
\begin{aligned}
& \mathrm{CuSO}_{4} \cdot 5 \mathrm{H}_{2} \mathrm{O}+\mathrm{H}_{2} \mathrm{VPA}+\text { phen } \\
& \stackrel{\text { water }}{\longrightarrow}\left[\mathrm{Cu}\left(\mu-\mathrm{SO}_{4}\right)(\text { phen })\left(\mathrm{H}_{2} \mathrm{O}\right)_{2}\right]_{\infty}(\mathbf{2})+5 \mathrm{H}_{2} \mathrm{O} \\
& \quad+\mathrm{H}_{2} \mathrm{VPA}(\text { unreacted })
\end{aligned}
$$

It should be noted that 2 does not form in the absence of $\mathrm{H}_{2}$ VPA under the same conditions. It is likely that $\mathrm{H}_{2}$ VPA has a templating role in the reaction.

The purity of compounds $\mathbf{1}$ and $\mathbf{2}$ was evaluated by XRPD, revealing a good agreement between the simulated X-ray diffraction patterns from the single-crystal data and those obtained for the polycrystalline samples (Figure S1 in the Supporting Information).

The TGA curves for both compounds, 1 and 2, are given in Figure S2 in the Supporting Information. Compound $\mathbf{1}$ undergoes several consecutive weight loss steps from room temperature up to $160{ }^{\circ} \mathrm{C}$ corresponding to the removal of the eight lattice and two coordinated water molecules. According to the TG curve and the thermodiffractometric study (Figures S2 and S3 in the Supporting Information) of solid 1, the first weight loss, between 50 and $80{ }^{\circ} \mathrm{C}$, corresponds to the loss of six lattice water molecules (calculated weight loss $12.27 \%$; observed, $12.43 \%$ ), while the loss of the two additional lattice water molecules takes place between 80 and $120{ }^{\circ} \mathrm{C}$ (calculated weight loss up to $120{ }^{\circ} \mathrm{C}, 16.36 \%$; observed, $15.83 \%)$. Finally, the coordinated water molecules are lost in the range $120-160{ }^{\circ} \mathrm{C}$. The total weight loss, $20.49 \%$, is in good agreement with the calculated one, $20.46 \%$. Each dehydration stage has associated structural modifications which lead to an anhydrous semicrystalline phase. No additional weight loss is observed up to $370{ }^{\circ} \mathrm{C}$ temperature, at which the decomposition of the compound begins. The rehydration of solid 1 takes place after exposing for several days the anhydrous phase at high humidity atmosphere (98\% $\mathrm{RH}$ ) obtained by a saturated $\mathrm{K}_{2} \mathrm{SO}_{4}$ solution in a closed vessel. The weight loss found by thermal analysis (Figure S2 in the Supporting Information), 18.6\%, agrees well with the uptake of nine water molecules (calculated, 18.4\%). The rehydration process leads to a new semicrystalline compound, for which the XRPD pattern could not be indexed, with diffraction peaks at higher $d$-space than the original solid (Figure S3 in the Supporting Information). This fact suggests a different arrangement of the dinuclear $\mathrm{Cu}(\mathrm{II})$ unit, as well as of the incorporated lattice water molecules after rehydration.

The TG curve of compound $\mathbf{2}$ and its thermodiffractometric study (Figures S2 and S3 in the Supporting Information) confirm that the coordinated water molecules are lost between 120 and $160{ }^{\circ} \mathrm{C}$ (calculated weight loss, 9.57\%; observed,
9.65\%) giving a semicrystalline anhydrous phase that remains stable up to $340^{\circ} \mathrm{C}$. Above this temperature, decomposition of the solid takes place. Rehydration of the anhydrous compound does not take place upon cooling although it is fully reversible after exposing the sample at high humidity for 3 days (Figure S3 in the Supporting Information).

Structural Description of 1 and 2. Compound 1 is composed of two symmetry equivalent $[\mathrm{Cu}(\mu$-VPA $)(\mathrm{phen})$ $\left.\left(\mathrm{H}_{2} \mathrm{O}\right)\right]$ units that are interconnected by the $\mu$-VPA linkers into the dicopper(II) complex with a $\mathrm{Cu} \cdots \mathrm{Cu}$ separation of $4.188 \AA$ Å, Figure 1 (left). Each structurally equivalent $\mathrm{Cu}^{2+}$ center is found in a square pyramidal $\left\{\mathrm{CuN}_{2} \mathrm{O}_{3}\right\}$ coordination environment. The pyramid base is formed by two $\mathrm{N}$ atoms from the chelating phen and two $\mathrm{O}$ atoms from two different VPA molecules. A water ligand occupies the pyramid apex.

$\mathrm{Cu}-\mathrm{N}$ bond distances $[2.018(2) \AA$ and 2.024(2) $\AA]$ are within the reported values. ${ }^{53} \mathrm{Cu}-\mathrm{O}(\mathrm{P})$ bonds $[1.9059(19) \AA$ and $1.9260(18) \AA]$ fall within the reported range of similar $\mathrm{Cu}-\mathrm{O}$ (phosphonate) distances. ${ }^{54}$ The $\mathrm{Cu}-\mathrm{O}\left(\mathrm{H}_{2} \mathrm{O}\right)$ bond is elongated $[2.3829(19) \AA]$ due to the Jahn-Teller effect. ${ }^{55}$ There are two "short" $\mathrm{P}-\mathrm{O}$ distances $[1.5213(19)$ and $1.516(2) \AA]$ corresponding to the $\mathrm{P}-\mathrm{O}(\mathrm{Cu})$ bonds and one "long" uncoordinated $\mathrm{P}=\mathrm{O}$ bond $[1.544(2) \AA]$.

The dimers interact via two kinds of weak interactions: hydrogen bonds via the lattice and coordinated water molecules, and $\pi-\pi$ interactions of the phen aromatic rings. Due to the opposite arrangement of the neighboring phen rings, two $\pi-\pi$ interactions (centroid-to-centroid distance $3.614 \AA$ ) are formed between the pyridyl edge rings, Figure 1, right.

There are a total of ten water molecules (eight in the lattice and two ligands) per dimeric unit of $\mathbf{1}$. Hence, there is a plethora of hydrogen bonds with the $\mathrm{O} \cdots \mathrm{O}$ distances ranging from 2.736 to $2.865 \AA$ (Figure S4 in the Supporting Information), which lead to a generation of water clusters and an extension of the structure (see below).

The structure of $\mathbf{2}$ has been reported before. ${ }^{40}$ However, herein we will present some salient structural features of $\mathbf{2}$ that will be useful in rationalizing the proton conductivity processes that will be discussed later. Compound 2 is a $1 \mathrm{D}$ linear chain coordination polymer (Figure 2).

The $\mathrm{Cu}^{2+}$ centers are found in an octahedral $\left\{\mathrm{CuN}_{2} \mathrm{O}_{4}\right\}$ environment. The octahedron base is formed by the two $\mathrm{N}$ atoms of the chelating phen ligand $[\mathrm{Cu}-\mathrm{N}$ distance $2.0099(29) \AA]$ and the two water molecules $[\mathrm{Cu}-\mathrm{O}$ distance $1.9714(26) \AA]$ in a cis configuration. The axial ligands are $\mathrm{O}$ atoms from the bridging sulfate dianion $[\mathrm{Cu} \cdots \mathrm{Cu}$ distance $7.006 \AA, \mathrm{Cu}-\mathrm{O}$ (sulfate) distance $2.4592(28) \AA$, similar to the 


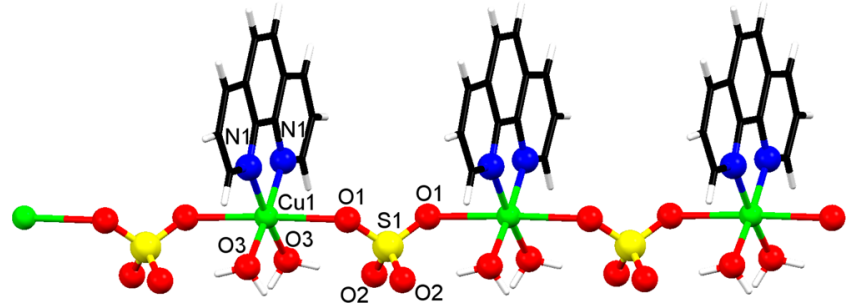

Figure 2. Portion of the 1D metal-organic chain in 2, showing the chelating phen ligands, the bridging sulfates, and the coordinated water molecules. Only selected atoms are labeled.

$\mathrm{Cu}-\mathrm{O}$ (sulfate) distances in $\mathrm{CuSO}_{4} \cdot 5 \mathrm{H}_{2} \mathrm{O} .{ }^{56}$ The $1 \mathrm{D}$ chains in 2 interact via two interchain "double" hydrogen bonds which develop between the $\mathrm{Cu}$-coordinated water ligands and the

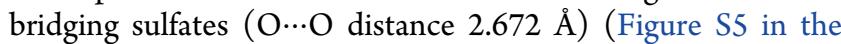
Supporting Information, left). There is also an intrachain hydrogen bond between one of the water molecules and the sulfate ( $\mathrm{O} \cdots \mathrm{O}$ distance $2.608 \AA$ ). Interlocking $\pi-\pi$ interactions also develop between the benzene rings (centroid-to-centroid distance $3.520 \AA$ ) (Figure S5 in the Supporting Information, right).

H-Bonded Nets and Topological Analysis. The structure of 1 features a discrete dicopper(II) $\left[\mathrm{Cu}_{2}(\mu\right.$ $\mathrm{VPA})_{2}$ (phen $\left.)_{2}\left(\mathrm{H}_{2} \mathrm{O}\right)_{2}\right]$ molecular unit and eight crystallization water molecules. The latter are assembled by hydrogen bonds into a pair of acyclic tetrameric $\left(\mathrm{H}_{2} \mathrm{O}\right)_{4}$ clusters (Figure 3a). These clusters can be extended to more complex $\left(\mathrm{H}_{2} \mathrm{O}\right)_{5}$ aggregates if considering an additional interaction with $\mathrm{H}_{2} \mathrm{O}$ ligand. According to the classification of discrete water clusters, ${ }^{57}$ the identified $\left(\mathrm{H}_{2} \mathrm{O}\right)_{4}$ and $\left(\mathrm{H}_{2} \mathrm{O}\right)_{5}$ associates can be classified within the $D 3$ and $R 4$ type, respectively. ${ }^{58,59}$ The adjacent dicopper(II) blocks and $\left(\mathrm{H}_{2} \mathrm{O}\right)_{4}$ clusters are multiply interlinked by strong $\mathrm{H}$-bonds, resulting in the generation of intricate 2D $\mathrm{H}$-bonded layers (Figure 3).

Topological analysis of the underlying 2D layers in $\mathbf{1}$ (Figure $3 \mathrm{~b})$ reveals that they are composed of the 6-connected $\left[\mathrm{Cu}_{2}(\mu\right.$ VPA $)_{2}$ (phen $\left.)_{2}\left(\mathrm{H}_{2} \mathrm{O}\right)_{2}\right]$ molecular nodes and the 3-connected $\left(\mathrm{H}_{2} \mathrm{O}\right)_{4}$ nodes. This net can be classified as a binodal 3,6connected layer with the kgd [Shubnikov plane net (3.6.3.6)/ dual] topology. It is described by the point symbol of $\left(4^{3}\right)_{2}\left(4 \cdot{ }^{6} 6 \cdot{ }^{6} 8^{3}\right)$, wherein the $\left(4^{3}\right)$ and $\left(4 \cdot{ }^{6} 6 \cdot{ }^{6} 8^{3}\right)$ notations are those of the dicopper(II) and $\left(\mathrm{H}_{2} \mathrm{O}\right)_{4}$ nodes, respectively.

In 2, two adjacent $1 \mathrm{D}$ metal-organic chains feature intermolecular hydrogen bonds between water ligands and sulfate linkers, thus resulting in the formation of a more complex double chain (Figure 4a). From the topological perspective, an underlying double chain is built from the 3connected $\left[\mathrm{Cu}(\mathrm{phen})\left(\mathrm{H}_{2} \mathrm{O}\right)_{2}\right]^{2+}$ and $\mu-\mathrm{SO}_{4}{ }^{2-}$ nodes that are topologically equivalent (Figure $4 \mathrm{~b}$ ). As a result, such chain can be classified as a uninodal 3-connected network with the SP 1-periodic net $(4,4)(0,2)$ topology and point symbol of $\left(4 \cdot{ }^{2} 6\right)$.

Proton Conductivity Studies. Impedance measurements were carried out between 80 and $25{ }^{\circ} \mathrm{C}$ at $95 \%$ relative humidity $(\mathrm{RH})$. The overall pellet conductivities, determined from the semicircles in the Nyquist plots (Figure S6 in the Supporting Information), are presented in Figure 5 in a traditional Arrhenius plot.

Both compounds 1 and 2 display similar proton conductivity values, $3.65 \times 10^{-6}$ and $3.94 \times 10^{-6} \mathrm{~S} \cdot \mathrm{cm}^{-1}$, respectively, measured at $80{ }^{\circ} \mathrm{C}$ and $95 \% \mathrm{RH}$. This level of conductivity may be due to the absence of readily ionizable acid groups in their H-bonded or metal-organic networks as observed for other coordination polymers. ${ }^{6,61}$ However, the proton transfer mechanism exhibited by both compounds is quite different. Likely, the more acidic coordinated water molecules $[\mathrm{Cu}-$ $\left.\mathrm{O}\left(\mathrm{H}_{2} \mathrm{O}\right) \sim 1.97 \AA\right]$ in 2 together with their stronger H-bond interactions with the oxygen atoms of sulfate groups $(\mathrm{O} \cdots \mathrm{O}$ distance $2.608 \AA$ ) (Figure 5) favor the hopping of protons between them, which is consistent with a Grotthuss-like mechanism and low activation energy $(0.26 \mathrm{eV})$. In contrast, the less acidic coordinated water in compound $1[\mathrm{Cu}-$ $\left.\mathrm{O}\left(\mathrm{H}_{2} \mathrm{O}\right) \sim 2.38 \AA\right]$ together with weaker $\mathrm{H}$-bond interactions (D)A > $2.7 \AA$ ) between the bonded/lattice water molecules and the $\mathrm{O}$ atoms of the phosphonate group (Figures 1 and 3 ) suggest that a vehicle-type mechanism prevails in $\mathbf{1}$ with a higher activation energy $(0.59 \mathrm{eV}) .^{61-63}$

After impedance measurements, pelletized samples were analyzed by XRPD (Figure S7 in the Supporting Information) and TGA (Figure S8 in the Supporting Information) to notice possible structural and/or water content changes. The XRPD patterns did not reveal significant changes, as compared to the initial sample, and no significant weight gain was observed. In

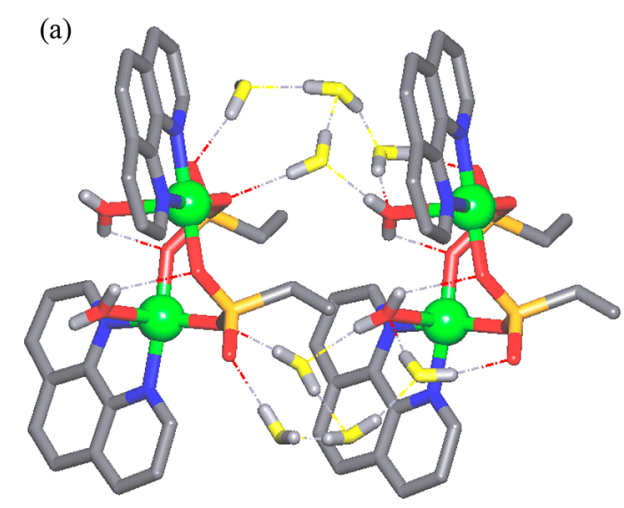

(b)

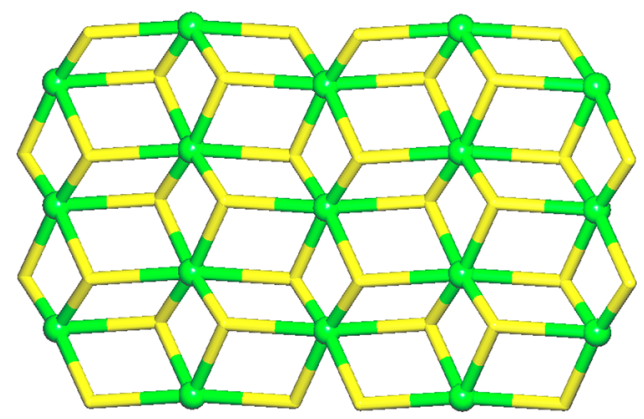

Figure 3. Structural fragments of 1. (a) H-bonding interlinkage of two dicopper(II) molecular units $\left[\mathrm{Cu}_{2}(\mu \text {-VPA })_{2}(\mathrm{phen})_{2}\left(\mathrm{H}_{2} \mathrm{O}\right)_{2}\right]$ with $\left(\mathrm{H}_{2} \mathrm{O}\right)_{4}$ clusters; water $\mathrm{O}$ atoms within $\left(\mathrm{H}_{2} \mathrm{O}\right)_{4}$ clusters are shown in yellow; $\mathrm{Cu}$ (green balls), $\mathrm{O}$ (red), $\mathrm{N}$ (blue), $\mathrm{P}$ (orange), $\mathrm{C}$ (gray), $\mathrm{H}$ (pale gray). (b) Topological representation of the underlying 2D H-bonded network showing a binodal 3,6-connected layer with the kgd [Shubnikov plane net (3.6.3.6)/dual] topology; view along the $a$ axis; centroids of 6-connected dicopper(II) molecular nodes (green balls), centroids of 3-connected $\left(\mathrm{H}_{2} \mathrm{O}\right)_{4}$ nodes (yellow). 
(a)

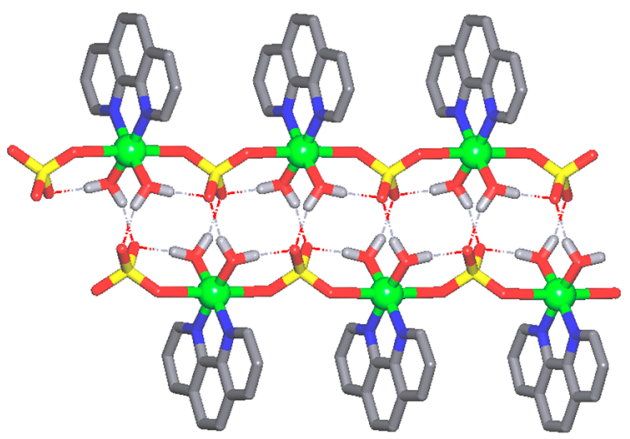

(b)

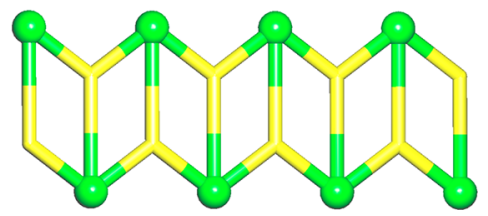

Figure 4. Structural fragments of 2. (a) H-bonding interlinkage of two linear $1 \mathrm{D}$ metal-organic chains into a double chain; $\mathrm{Cu}$ (green balls), $\mathrm{O}$ (red), N (blue), S (yellow), C (gray), H (pale gray). (b) Topological representation of the underlying 1D H-bonded network showing a uninodal 3-connected double chain with the SP 1-periodic net $(4,4)(0,2)$ topology; view along the $a$ axis; centroids of 3-connected $\left[\mathrm{Cu}(\mathrm{phen})\left(\mathrm{H}_{2} \mathrm{O}\right)_{2}\right]^{2+}$ nodes (green balls), centroids of 3 -connected $\mu-\mathrm{SO}_{4}{ }^{2-}$ nodes (yellow).

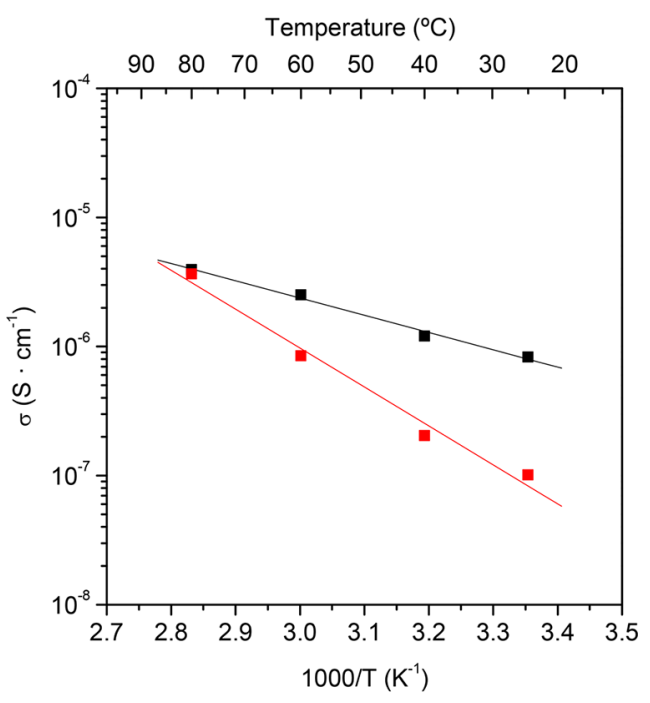

Figure 5. Arrhenius plots for $\mathbf{1}$ (red) and $\mathbf{2}$ (black) at $95 \%$ of relative humidity $(\mathrm{RH})$.

addition, the water content of compound $\mathbf{1}$ was also determined by thermal analysis after keeping the sample for $4 \mathrm{~h}$ at $80{ }^{\circ} \mathrm{C}$ and $95 \% \mathrm{RH}$ (Figure S8 in the Supporting Information). The observed weight loss confirms that the compound maintains the same hydration degree as the assynthesized sample. The high relative humidity inside the chamber used for the proton conductivity measurements prevents dehydration of the sample and shifts it to higher temperatures than those shown by the thermodiffractometric study carried out under dry conditions.

Mild Catalytic Oxidation of Cycloalkanes. Compound 1 was also tested in the mild homogeneous oxidation of $\mathrm{C}_{5}-\mathrm{C}_{8}$ cycloalkanes, by aqueous $\mathrm{H}_{2} \mathrm{O}_{2}$ in $\mathrm{MeCN} / \mathrm{H}_{2} \mathrm{O}$ medium at 50 ${ }^{\circ} \mathrm{C}$, to give a mixture of the corresponding cyclic alcohols and ketones (Scheme 1). The oxidation of cycloalkanes proceeds with comparable reaction rates but results in slightly different

Scheme 1. Oxidation of $\mathrm{C}_{5}-\mathrm{C}_{8}$ Cycloalkanes

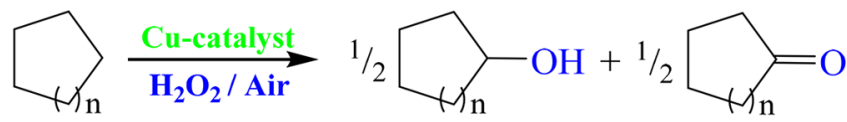

$n=1-4$ total yields (Figure 6). Hence, the oxidations of cyclohexane and cycloheptane are slightly more efficient (maximum total product yields of $\sim 23 \%$ and $\sim 20 \%$, respectively) than those of cyclopentane and cyclooctane (total yields of $\sim 17-18 \%$ ). Hereinafter all the yields are relative to cycloalkane substrate.

In the oxidation of cyclopentane (Figure 6a), cyclopentanone is formed predominantly to cyclopentanol along all the reaction time. In the case of cyclohexane oxidation (Figure $6 \mathrm{~b})$, cyclohexanol is formed predominantly ( 2:1 molar ratio) to cyclohexanone in the beginning of the reaction; however, their yields become comparable with time. The yields of both oxidation products are similar in the oxidation of cycloheptane (Figure 6c). Interestingly, cyclooctanone is a predominant product in the oxidation of cyclooctane (Figure $6 \mathrm{~d})$.

For comparative purposes, the oxidation of cyclohexane in the presence of catalyst 2 was also investigated (Figure 7). Given the presence of only one $\mathrm{Cu}$ atom per formula unit, an excess of $2(20 \mu \mathrm{mol})$ was used in comparison with $\mathbf{1}$ (10 $\mu \mathrm{mol})$. A lag period is observed for 2 within the initial $90 \mathrm{~min}$ of the oxidation reaction. After this period, the reaction rate increases significantly but the activity of $\mathbf{2}$ does not reach the level showed by $\mathbf{1}$. Such a lag period can potentially be related with a $1 \mathrm{D}$ polymeric nature of 2 , wherein additional time is required for a partial disaggregation of the network and generation of a catalytically active species.

The obtained yields of oxygenates can be considered as rather good in the field of mild oxidative functionalization of alkanes. ${ }^{39,64-66}$ For example, an industrial DuPont process of the cyclohexane oxidation operates with a homogeneous cobalt naphthenate catalyst and proceeds only with $\sim 5 \%$ cyclohexane conversion under harsher reaction conditions. ${ }^{67}$ Moreover, catalyst 1 does not require the use of an acid-type promoter or cocatalyst, which is usually required by various catalytic systems for the mild oxidation of alkanes. ${ }^{39,68,69}$

Mild Catalytic Hydrocarboxylation of Cycloalkanes. Compound 1 was also applied as an efficient catalyst for the hydrocarboxylation of $\mathrm{C}_{5}-\mathrm{C}_{8}$ cycloalkanes (Scheme 2). This transformation consists of treating a cycloalkane substrate with CO (carbonyl source), potassium peroxodisulfate (oxidant), and $\mathrm{H}_{2} \mathrm{O}$ (hydroxyl source) to form a cycloalkanecarboxylic acid in a single-step. ${ }^{70}$ The hydrocarboxylation occurs in $\mathrm{H}_{2} \mathrm{O}$ / $\mathrm{MeCN}$ medium at $60{ }^{\circ} \mathrm{C}$ and requires the use of a homogeneous metal containing catalyst. The obtained results on the activity of $\mathbf{1}$ are summarized in Table 2 . 
(a)

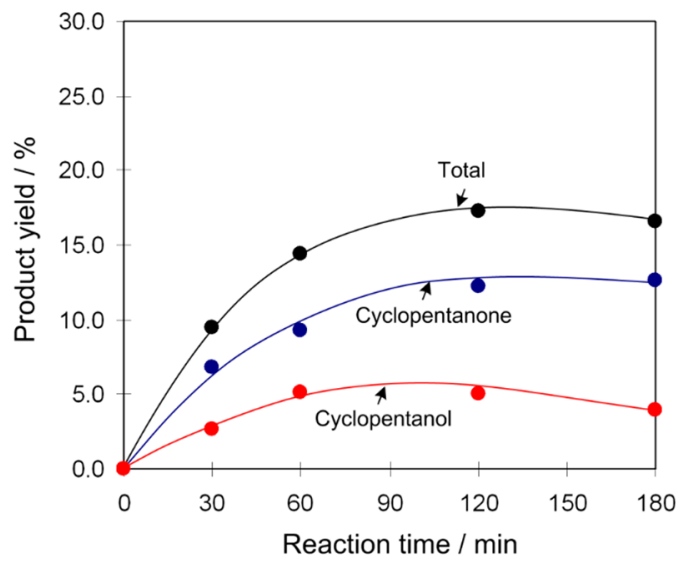

(c)

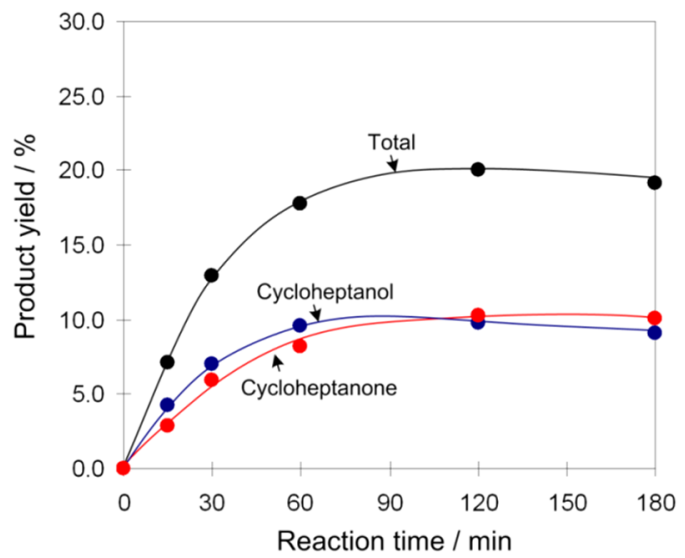

(b)

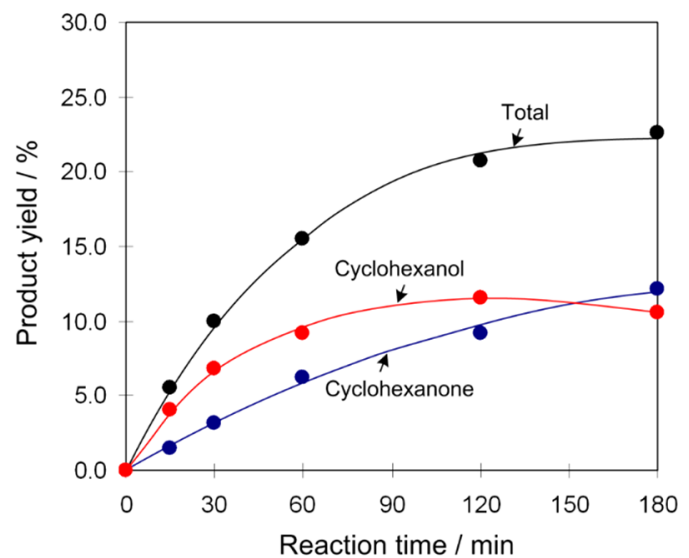

(d)

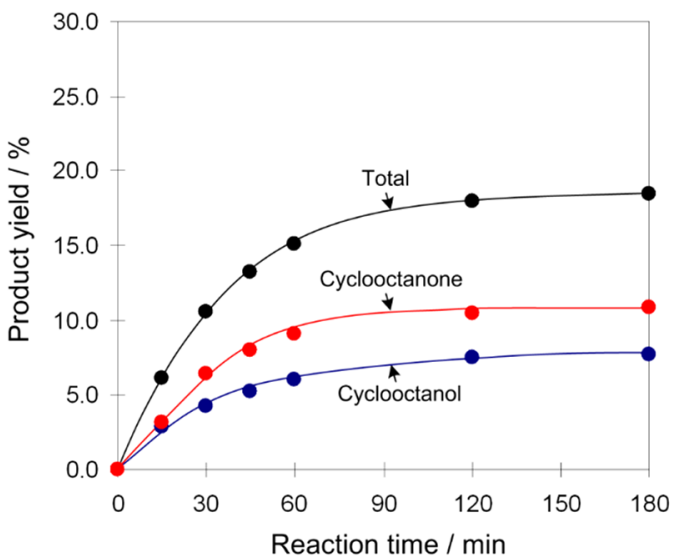

Figure 6. Product accumulation curves in the oxidation of (a) cyclopentane, (b) cyclohexane, (c) cycloheptane, and (d) cyclooctane with $\mathrm{H}_{2} \mathrm{O}_{2}$ catalyzed by 1 . Reaction conditions: $1(10 \mu \mathrm{mol})$, cycloalkane $(2.0 \mathrm{mmol}), \mathrm{H}_{2} \mathrm{O}_{2}\left(10.0 \mathrm{mmol} ; 50 \%\right.$ in $\left.\mathrm{H}_{2} \mathrm{O}\right), \mathrm{CH}_{3} \mathrm{CN}$ (up to $5.0 \mathrm{~mL}$ total volume), $50{ }^{\circ} \mathrm{C}$.

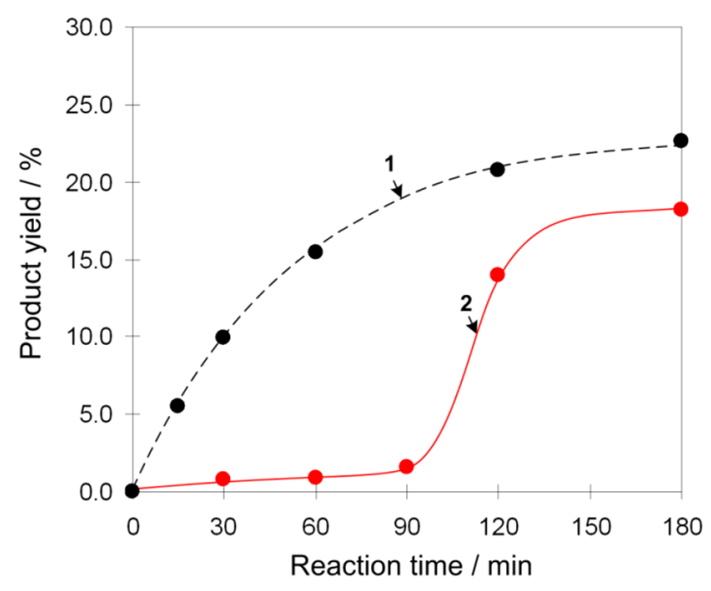

Figure 7. Product accumulation curves in the oxidation of cyclohexane with $\mathrm{H}_{2} \mathrm{O}_{2}$ catalyzed by 1 and 2 . Reaction conditions: $1(10 \mu \mathrm{mol})$ or $2(20 \mu \mathrm{mol})$, cyclohexane $(2.0 \mathrm{mmol}), \mathrm{H}_{2} \mathrm{O}_{2}(10.0$ $\mathrm{mmol}, 50 \%$ in $\mathrm{H}_{2} \mathrm{O}$ ), $\mathrm{CH}_{3} \mathrm{CN}$ (up to $5.0 \mathrm{~mL}$ total volume), $50{ }^{\circ} \mathrm{C}$.

The hydrocarboxylation of $\mathrm{C}_{5}-\mathrm{C}_{8}$ cycloalkanes results in the formation of one monocarboxylic acid product due to the presence of a single type of carbon atom in substrate molecules. Cyclopentanecarboxylic or cyclohexanecarboxylic
Scheme 2. Hydrocarboxylation of $\mathrm{C}_{5}-\mathrm{C}_{8}$ Cycloalkanes

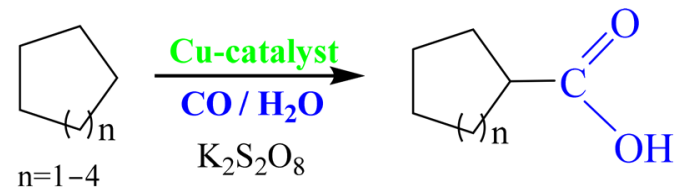

acids were generated in $30 \%$ or $29 \%$ yields, respectively; hereinafter all the yields are relative to cycloalkane substrate. Lower product yields were obtained in the reactions using cycloheptane and cyclooctane as substrates (19\% and 7\%, respectively). No dicarboxylic acid formation was observed during the reactions. Nevertheless, the corresponding cyclic ketones and alcohols were also formed as a result of partial cycloalkane oxidation. The total yield of oxygenates (ketone is formed predominantly to alcohol) increases with the hydrocarbon size, namely from $0.6 \%$ for $\mathrm{C}_{5} \mathrm{H}_{10}$ and $4.0 \%$ for $\mathrm{C}_{6} \mathrm{H}_{12}$ to $10.3 \%$ for $\mathrm{C}_{7} \mathrm{H}_{14}$ and $14.6 \%$ for $\mathrm{C}_{8} \mathrm{H}_{16}$. Interestingly, an opposite trend is observed when considering the yields of cycloalkanecarboxylic acids, which gradually decline on increasing the hydrocarbon ring size. For comparative purposes, the hydrocarboxylation of cyclohexane in the presence of catalyst $\mathbf{2}$ was also attempted, resulting in up to $34 \%$ total product yield. This is almost similar to that (33\%) 
Table 2. Single-Pot Hydrocarboxylation of $\mathrm{C}_{n}(n=5-8)$ Cycloalkanes into the Corresponding $\mathrm{C}_{n+1}$ Cycloalkanecarboxylic Acids. $^{a}$

\begin{tabular}{|c|c|c|c|c|c|c|}
\hline \multirow[b]{2}{*}{ Entry } & \multirow[b]{2}{*}{ Cycloalkane } & \multirow[b]{2}{*}{ Catalyst } & \multicolumn{4}{|c|}{ Product yield, $\%^{b}$} \\
\hline & & & $\begin{array}{l}\text { Carboxylic } \\
\text { acid }\end{array}$ & Ketone & Alcohol & Total $^{c}$ \\
\hline 1 & & 1 & 30.2 & 0.5 & 0.1 & 30.8 \\
\hline 2 & & 1 & 28.6 & 3.2 & 0.8 & 32.6 \\
\hline 3 & & 1 & 18.8 & 8.3 & 2.0 & 29.1 \\
\hline 4 & & 1 & 7.4 & 9.9 & 4.7 & 22.0 \\
\hline $5^{d}$ & & 2 & 30.1 & 3.3 & 0.9 & 34.3 \\
\hline
\end{tabular}

${ }^{a}$ Cyclic ketones and alcohols are also formed as products of cycloalkane oxidation. Reaction conditions (unless stated otherwise): cycloalkane (1.00 $\mathrm{mmol})$, catalyst $1(10 \mu \mathrm{mol}), p(\mathrm{CO})=20 \mathrm{~atm}, \mathrm{~K}_{2} \mathrm{~S}_{2} \mathrm{O}_{8}(1.50 \mathrm{mmol}), \mathrm{H}_{2} \mathrm{O}(2.0 \mathrm{~mL}) / \mathrm{MeCN}(4.0 \mathrm{~mL}), 60{ }^{\circ} \mathrm{C}, 3 \mathrm{~h}$ in an autoclave $(20.0 \mathrm{~mL}$ capacity). ${ }^{b}$ Moles of product $/ 100 \mathrm{~mol}$ of alkane determined by GC analysis. ${ }^{c}$ Yield of all products. ${ }^{d}$ Compound 2 was tested as catalyst $(20 \mu \mathrm{mol})$ for comparative purposes.

Scheme 3. Proposed Mechanism for Cu-Catalyzed Oxidation (a) and Hydrocarboxylation (b) of $\mathrm{C}_{5}-\mathrm{C}_{8} \mathrm{Cycloalkanes}$

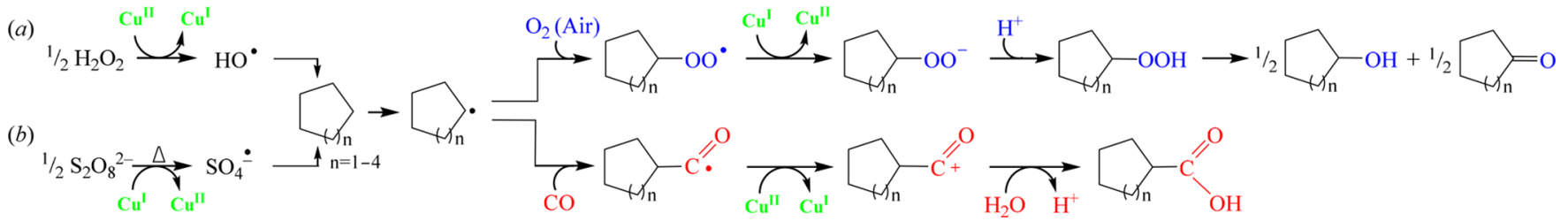

attained in the reaction catalyzed by $\mathbf{1}$, thus indicating a comparable activity of both catalysts.

Proposed Mechanism for Mild Oxidative Functionalization of Cycloalkanes. Considering our previous data and literature background on the mild $\mathrm{Cu}$-catalyzed oxidation ${ }^{37,38}$ and hydrocarboxylation ${ }^{70}$ of alkanes, the free radical mechanisms can be proposed for both types of model reactions studied in the present work (Scheme 3). Hence, in the oxidation of cycloalkanes (Scheme 3a), the copper catalyst facilitates the generation of hydroxyl radicals $\left(\mathrm{HO}^{\bullet}\right)$ that are the principal oxidizing species. The $\mathrm{HO}^{\bullet}$ radicals abstract $\mathrm{H}$ atoms from cycloalkane $(\mathrm{CyH})$ to form cycloalkyl radicals $\left(\mathrm{Cy}^{\bullet}\right)$, which then react with $\mathrm{O}_{2}$ (e.g., from air or formed from $\mathrm{H}_{2} \mathrm{O}_{2}$ ) to give rise to $\mathrm{CyOO}^{\bullet}$ radicals. The latter are transformed to $\mathrm{CyOO}^{-}$(followed by a regeneration of $\mathrm{Cu}^{\mathrm{II}}$ catalyst) and then to cycloalkyl hydroperoxides $(\mathrm{CyOOH})$ as primary intermediate products. $\mathrm{CyOOH}$ then rapidly decompose to form the corresponding cyclic alcohols and ketones as final products.

For the hydrocarboxylation of cycloalkanes (Scheme 3b), the free-radical mechanism begins from the thermal and/or $\mathrm{Cu}$-assisted generation of sulfate radical anions $\left(\mathrm{SO}_{4}{ }^{--}\right)$from peroxodisulfate. These radical anions are a key species to abstract $\mathrm{H}$ atoms from cycloalkanes $(\mathrm{CyH})$, leading to the formation of cycloalkyl radicals $\left(\mathrm{Cy}^{\bullet}\right)$. These then react with $\mathrm{CO}$ to produce cycloacyl radicals $\left(\mathrm{CyCO}^{\circ}\right)$, which are oxidized by $\mathrm{Cu}^{\mathrm{II}}$ to cycloacyl cations $\mathrm{CyCO}^{+}$(oxidation of $\mathrm{Cu}^{\mathrm{I}}$ by $\mathrm{K}_{2} \mathrm{~S}_{2} \mathrm{O}_{8}$ contributes to the regeneration of $\mathrm{Cu}^{\mathrm{II}}$ species). In the last step, the cycloacyl cations are hydrolyzed by $\mathrm{H}_{2} \mathrm{O}$ to furnish cycloalkanecarboxylic acids $(\mathrm{CyCOOH})$ as final products.

\section{CONCLUSIONS}

In this paper we reported the synthesis, structural characterization, topological analysis, proton conductivity, and catalytic properties of two di- or multicopper(II) compounds, containing the resembling $\left[\mathrm{Cu}(\text { phen })\left(\mathrm{H}_{2} \mathrm{O}\right)_{n}\right]^{2+}(n=1,2)$ blocks and anionic linkers $\left(\mu-\mathrm{VPA}^{2-}\right.$ or $\left.\mu-\mathrm{SO}_{4}{ }^{2-}\right)$. Both products $\mathbf{1}$ and 2 were generated under similar conditions except the reaction $\mathrm{pH}$, which is a key parameter that guides the structural differences between a OD copper(II) dimer $\mathbf{1}$ and a linear chain 1D coordination polymer 2 .

Structural features and $\mathrm{H}$-bonding interactions in the obtained compounds were investigated in detail, allowing identification and classification of tetrameric and pentameric water clusters in $\mathbf{1}$. Besides, the metal-organic structures of 1 and $\mathbf{2}$ are extended by multiple hydrogen bonds to more complex $2 \mathrm{D}$ or $1 \mathrm{D} \mathrm{H}$-bonded architectures, respectively. They were also classified from a topological perspective, disclosing the kgd [Shubnikov plane net (3.6.3.6)/dual] net in $\mathbf{1}$ and the SP 1-periodic net $(4,4)(0,2)$ in $\mathbf{2}$. Both compounds $\mathbf{1}$ and $\mathbf{2}$ are also moderate proton conductors, with proton conductivity values, $\sigma=3.65 \times 10^{-6}$ and $3.94 \times 10^{-6} \mathrm{~S} \cdot \mathrm{cm}^{-1}$, respectively (measured at $80{ }^{\circ} \mathrm{C}$ and $95 \%$ relative humidity). 
Furthermore, we showed that compounds $\mathbf{1}$ and $\mathbf{2}$ act as efficient homogeneous catalysts for the mild oxidative functionalization of $\mathrm{C}_{5}-\mathrm{C}_{8}$ cycloalkanes, namely cyclopentane, cyclohexane, cycloheptane, and cyclooctane. Specifically, 1 catalyzes the mild oxidation of cycloalkanes, by aqueous $\mathrm{H}_{2} \mathrm{O}_{2}$ in $\mathrm{MeCN} / \mathrm{H}_{2} \mathrm{O}$ medium at $50{ }^{\circ} \mathrm{C}$, to give a mixture of the corresponding cyclic alcohols and ketones with up to $23 \%$ total yields. Both copper(II) compounds are also active in the mild hydrocarboxylation of cycloalkanes, by $\mathrm{CO} / \mathrm{H}_{2} \mathrm{O}$ and $\mathrm{S}_{2} \mathrm{O}_{8}{ }^{2-}$ at $60{ }^{\circ} \mathrm{C}$ in $\mathrm{H}_{2} \mathrm{O} / \mathrm{MeCN}$ medium, allowing generation of the corresponding cycloalkanecarboxylic acids in up to $30 \%$ yields. These yields are rather high in the field of oxidative functionalization of alkanes, especially considering the high inertness of alkanes and mild reaction conditions (e.g., aqueous medium, $50-60{ }^{\circ} \mathrm{C}$ temperatures, absence of acid cocatalysts or promoters). Due to the homogeneous nature of the present catalytic systems, catalyst recovery still remains a challenging task. Hence, future studies can be devoted to the fabrication of recoverable heterogeneous catalytic systems that incorporate such copper(II) coordination compounds. Besides, further research on widening the family of related copper(II) catalysts and extending the substrate scope of catalytic transformations will be pursued.

\section{ASSOCIATED CONTENT}

\section{S Supporting Information}

The Supporting Information is available free of charge on the ACS Publications website at DOI: 10.1021/acs.inorgchem.8b01315.

TGA traces, simulated and experimental (as synthesized and after impedance spectroscopy) X-ray powder diffraction patterns, thermodiffractometry XRPD patterns, thermogravimetric analysis curves (as synthesized and after impedance spectroscopy), plots of complex impedance plane at various temperatures, and ATR-IR spectra, for compounds 1 and $\mathbf{2}$ (PDF)

\section{Accession Codes}

CCDC 1837061 contains the supplementary crystallographic data for this paper. These data can be obtained free of charge via www.ccdc.cam.ac.uk/data_request/cif, or by emailing data_request@ccdc.cam.ac.uk, or by contacting The Cambridge Crystallographic Data Centre, 12 Union Road, Cambridge CB2 1EZ, UK; fax: +44 1223336033.

\section{AUTHOR INFORMATION}

\section{Corresponding Authors}

*E-mail: kirillov@tecnico.ulisboa.pt (AMK).

*E-mail: demadis@uoc.gr (KDD).

\section{ORCID}

Duane Choquesillo-Lazarte: 0000-0002-7077-8972

Aurelio Cabeza: 0000-0002-1582-3240

Alexander M. Kirillov: 0000-0002-2052-5280

Konstantinos D. Demadis: 0000-0002-0937-8769

\section{Funding}

The work at UMA was funded by MAT2016-77648-R research grant (Spain), cofunded by FEDER and by Junta de Andalucia (Spain) FQM-1656. D.Ch.-L. acknowledges funding by the Excellence Network of Crystallography and Crystallization "Factoría de Crystallización" FIS2015-71928-REDC supported by Spanish MINECO and the Intramural CSIC (201730I019) project. This work was also supported by the Foundation for
Science and Technology (FCT) and Portugal 2020 (projects IF/01395/2013/CP1163/CT005, UID/QUI/00100/2013, and LISBOA-01-0145-FEDER-029697). The publication has been prepared with the support of the RUDN University Program 5-100. AMK acknowledges the COST Action CA15106 (CHAOS).

\section{Notes}

The authors declare no competing financial interest.

\section{REFERENCES}

(1) Metal Phosphonate Chemistry: From Synthesis to Applications; Clearfield, A., Demadis, K. D., Eds.; Royal Society of Chemistry: London, 2012.

(2) Taddei, M.; Costantino, F.; Vivani, R. Robust metal-organic frameworks based on tritopic phosphonoaromatic ligands. Eur. J. Inorg. Chem. 2016, 2016, 4300-4309.

(3) Goura, J.; Chandrasekhar, V. Molecular metal phosphonates. Chem. Rev. 2015, 115, 6854-6965.

(4) Zhu, Y.-P.; Ma, T.-Y.; Liu, Y.-L.; Ren, T.-Z.; Yuan, Z.-Y. Metal phosphonate hybrid materials: from densely layered to hierarchically nanoporous structures. Inorg. Chem. Front. 2014, 1, 360-383.

(5) Gagnon, K. J.; Perry, H. P.; Clearfield, A. Conventional and unconventional metal-organic frameworks based on phosphonate ligands: MOFs and UMOFs. Chem. Rev. 2012, 112, 1034-1054.

(6) Zarȩba, J. K. Tetraphenylmethane and tetraphenylsilane as building units of coordination polymers and supramolecular networks - A focus on tetraphosphonates. Inorg. Chem. Commun. 2017, 86, 172-186.

(7) Tomson, M. B.; Kan, A. T.; Oddo, J. E. Acid/base and metal complex solution chemistry of the polyphosphonate DTPMP versus temperature and ionic strength. Langmuir 1994, 10, 1442-1449.

(8) Cigala, R. M.; Cordaro, M.; Crea, F.; De Stefano, C.; Fracassetti, V.; Marchesi, M.; Milea, D.; Sammartano, S. Acid-base properties and alkali and alkaline earth metal complex formation in aqueous solution of diethylenetriamine- $\mathrm{N}, \mathrm{N}, \mathrm{N}^{\prime}, \mathrm{N}^{\prime \prime}, \mathrm{N}^{\prime \prime}$ - pentakis(methylenephosphonic acid) obtained by an efficient synthetic procedure. Ind. Eng. Chem. Res. 2014, 53, 9544-9553.

(9) Hou, X.; Tang, S.-F. An investigation on the structural diversification of metal phosphonates in varying combinations of phosphonate ligand, metal ions and auxiliary ligands. Inorg. Chim. Acta 2018, 473, 169-179.

(10) Su, H.-Q.; Ma, K.-R.; Kan, Y.-H.; Qian, X.-D.; Hu, H.-Y.; Li, R.Q. Synthesis, structure and properties of a new $\mathrm{Co}$ (II) diphosphonate based on auxiliary ligand 2,2'-bipyridine. Inorg. Nano-Met. Chem. 2017, 47, 608-613.

(11) Wu, H.; Sun, W.; Shi, T.; Liao, X.; Zhao, W.; Yang, X. The various architectures and properties of a series of coordination polymers tuned by the central metals and auxiliary $\mathrm{N}$-donor ligands. CrystEngComm 2014, 16, 11088-11095.

(12) Dan, W.; Liu, X.; Deng, M.; Ling, Y.; Chen, Z.; Zhou, Y. A highly stable indium phosphonocarboxylate framework as a multifunctional sensor for $\mathrm{Cu}^{2+}$ and methylviologen ions. Dalton Trans. 2015, 44, 3794-3800.

(13) Mao, J.-G. Metal phosphonates and arsonates containing an auxiliary ligand. In Metal Phosphonate Chemistry: From Synthesis to Applications; Clearfield, A., Demadis, K. D., Eds.; Royal Society of Chemistry: London, 2012; Chapter 5, pp 133-169.

(14) Therrien, B. Coordination chemistry of 2,4,6-tri(pyridyl)-1,3,5triazine ligands. J. Organomet. Chem. 2011, 696, 637-651.

(15) Li, M.-Y.; Wang, F.; Zhang, J. Synthesis, structure and proton conductivity of a metal-organic framework with rich hydrogen-bonds between the layers. Inorg. Chem. Commun. 2017, 79, 37-40.

(16) Bulut, A.; Wörle, M.; Zorlu, Y.; Kirpi, E.; Kurt, H.; Zubieta, J.; Grabowsky, S.; Beckmann, J.; Yücesan, G. Acta Crystallogr., Sect. B: Struct. Sci., Cryst. Eng. Mater. 2017, B73, 296-303.

(17) Narang, S.; Singh, U. P.; Venugopalan, P. Solvent-mediated supramolecular template assembly of a metal organophosphonate via 
a crystal-amorphous-crystal transformation. CrystEngComm 2016, $18,54-61$.

(18) Kondo, A.; Satomi, T.; Azuma, K.; Takeda, R.; Maeda, K. New layered copper 1,3,5-benzenetriphosphonates pillared with $\mathrm{N}$-donor ligands: their synthesis, crystal structures, and adsorption properties. Dalton Trans. 2015, 44, 12717-12725.

(19) Cong, M.-H.; Ma, K.-R.; Kan, Y.-H.; Dong, X.-X. Structure, spectroscopy and DFT studies of a novel one-dimensional $\mathrm{Cu}^{\text {II }}$ diphosphonate coordination polymer. J. Iran. Chem. Soc. 2015, 12, 205-211.

(20) Lin, K.-J.; Fu, S.-J.; Cheng, C.-Y.; Chen, W.-H.; Kao, H.-M. Towards electrochemical artificial muscles: A supramolecular machine based on a one-dimensional copper-containing organophosphonate system. Angew. Chem. 2004, 116, 4282-4285.

(21) Du, M.; Li, C.-P.; Liu, C.-S.; Fang, S.-M. Design and construction of coordination polymers with mixed-ligand synthetic strategy. Coord. Chem. Rev. 2013, 257, 1282-1305.

(22) Zhu, Y.-P.; Ren, T.-Z.; Yuan, Z.-Y. Insights into mesoporous metal phosphonate hybrid materials for catalysis. Catal. Sci. Technol. 2015, 5, 4258-4279.

(23) Yang, Y.; Gao, C.-Y.; Tian, H.-R.; Ai, J.; Min, X.; Sun, Z. M. A highly stable MnII phosphonate as a highly efficient catalyst for $\mathrm{CO} 2$ fixation under ambient conditions. Chem. Commun. 2018, 54, 17581761.

(24) Bhanja, P.; Ghosh, K.; Islam, S. S.; Patra, A. K.; Islam, S. M.; Bhaumik, A. New hybrid iron phosphonate material as an efficient catalyst for the synthesis of adipic acid in air and water. ACS Sustainable Chem. Eng. 2016, 4, 7147-7157.

(25) Cai, Z.-S.; Shi, Y.; Bao, S.-S.; Shen, Y.; Xia, X.-H.; Zheng, L.-M. Bioinspired engineering of cobalt-phosphonate nanosheets for robust hydrogen evolution reaction. ACS Catal. 2018, 8, 3895-3902.

(26) Saha, J.; Chowdhury, D. R.; Jash, P.; Paul, A. Cobalt phosphonates as precatalysts for water oxidation: Role of pore size in catalysis. Chem. - Eur. J. 2017, 23, 12519-12526.

(27) Mendes, R. F.; Antunes, M. M.; Silva, P.; Barbosa, P.; Figueiredo, F.; Linden, A.; Rocha, J.; Valente, A. A.; Almeida Paz, F. A. A lamellar coordination polymer with remarkable catalytic activity. Chem. - Eur. J. 2016, 22, 13136-13146.

(28) Wang, J.; Niu, Y.; Zhang, M.; Ma, P.; Zhang, C.; Niu, J.; Wang, J. Organophosphonate-functionalized lanthanopolyoxomolybdate: Synthesis, characterization, magnetism, luminescence, and catalysis of $\mathrm{H}_{2} \mathrm{O}_{2}$-based thioether oxidation. Inorg. Chem. 2018, 57, 17961805.

(29) Wang, J.; Wang, R.; Zi, H.; Wang, H.; Xia, Y.; Liu, X. Porous organic zirconium phosphonate as efficient catalysts for the catalytic transfer hydrogenation of ethyl levulinate to $\gamma$-valerolactone without external hydrogen. J. Chin. Chem. Soc. 2018, 65, 750-759.

(30) Chen, X.; Peng, Y.; Han, X.; Liu, Y.; Lin, X.; Cui, Y. Sixteen isostructural phosphonate metal-organic frameworks with controlled Lewis acidity and chemical stability for asymmetric catalysis. Nature Comm. 2017, 8, Article number: 2171.

(31) Fang, W.-H.; Zhang, L.; Zhang, J. Synthetic investigation, structural analysis and photocatalytic study of a carboxylatephosphonate bridged $\mathrm{Ti}_{18}$-oxo cluster. Dalton Trans. 2017, 46, 803-807.

(32) Evans, O. R.; Ngo, H. L.; Lin, W. Chiral porous solids based on lamellar lanthanide phosphonates. J. Am. Chem. Soc. 2001, 123, 10395-10396.

(33) Olah, G. A.; Molnar, A.; Surya Prakash, G. K. Hydrocarbon chemistry; Wiley: New York, 2017.

(34) Shilov, A. E.; Shul'pin, G. B. Activation and catalytic reactions of saturated hydrocarbons in the presence of metal complexes; Springer: Berlin, 2006.

(35) Karlin, K. D., Tyeklar, Z., Eds. Bioinorganic Chemistry of Copper; Springer: Berlin, 2012.

(36) Itoh, S., Rokita, S., Eds. Copper-Oxygen Chemistry; Wiley: New York, 2011.

(37) Fernandes, T. A.; Santos, C. I. M.; André, V.; Kłak, J.; Kirillova, M. V.; Kirillov, A. M. Copper(II) coordination polymers self- assembled from aminoalcohols and pyromellitic acid: Highly active precatalysts for the mild water-promoted oxidation of alkanes. Inorg. Chem. 2016, 55, 125-135.

(38) Dias, S. S. P.; Kirillova, M. V.; André, V.; Kłak, J.; Kirillov, A. M. New tetracopper(II) cubane cores driven by a diamino alcohol: Selfassembly synthesis, structural and topological features, and magnetic and catalytic oxidation properties. Inorg. Chem. 2015, 54, 5204-5212.

(39) Kirillov, A. M.; Shul'pin, G. B. Pyrazinecarboxylic acid and analogs: highly efficient co-catalysts in the metal-complex-catalyzed oxidation of organic compounds. Coord. Chem. Rev. 2013, 257, 732754.

(40) Healy, P. C.; Patrick, J. M.; White, A. H. Crystal structure of Diaqua(1,10-phenanthroline) copper(II) sulfate. Aust. J. Chem. 1984, 37, $1111-1115$.

(41) APEX2, Software, V2014.11; Bruker AXS, Inc.: Madison, Wisconsin, USA, 2014.

(42) SADABS: Program for Empirical Absorption Correction of Area Detector Data; University of Goettingen: Germany, 2012.

(43) Sheldrick, G. M. A short history of SHELX. Acta Crystallogr., Sect. A: Found. Crystallogr. 2008, A64, 112-122.

(44) Blatov, V. A. Multipurpose crystallochemical analysis with the program package TOPOS. IUCr CompComm Newsletter 2006, 7, 438.

(45) Blatov, V. A.; Shevchenko, A. P.; Proserpio, D. M. Applied topological analysis of crystal structures with the program package ToposPro. Cryst. Growth Des. 2014, 14, 3576-3586.

(46) O'Keeffe, M.; Yaghi, O. M. Deconstructing the crystal structures of metal-organic frameworks and related materials into their underlying nets. Chem. Rev. 2012, 112, 675-702.

(47) Li, M.; Li, D.; O’Keeffe, M.; Yaghi, O. M. Topological analysis of metal-organic frameworks with polytopic linkers and/or multiple building units and the minimal transitivity principle. Chem. Rev. 2014, $114,1343-1370$

(48) Shul'pin, G. B. Metal-catalyzed hydrocarbon oxygenations in solutions: The dramatic role of additives: a review. J. Mol. Catal. A: Chem. 2002, 189, 39-66.

(49) Shul'pin, G. B. Hydrocarbon oxygenations with peroxides catalyzed by metal compounds. Mini-Rev. Org. Chem. 2009, 6, 95104.

(50) Ziegler, A.; Landfester, K.; Musyanovych, A. Synthesis of phosphonate-functionalized polystyrene and poly(methyl methacrylate) particles and their kinetic behavior in miniemulsion polymerization. Colloid Polym. Sci. 2009, 287, 1261-1271.

(51) Bingöl, B.; Meyer, W. H.; Wagner, M.; Wegner, G. Synthesis, micro-structure, and acidity of poly(vinylphosphonic acid). Macromol. Rapid Commun. 2006, 27, 1719-1724.

(52) Demadis, K. D.; Lykoudis, P.; Raptis, R. G.; Mezei, G. Phosphonopolycarboxylates as chemical additives for calcite scale dissolution and metallic corrosion inhibition based on a calciumphosphonotricarboxylate organic-inorganic hybrid. Cryst. Growth Des. 2006, 6, 1064-1067.

(53) Demadis, K. D.; Panera, A.; Anagnostou, Z.; Varouhas, D.; Kirillov, A. M.; Cisarova, I. Disruption of "coordination polymer" architecture in $\mathrm{Cu}^{2+}$ bis-phosphonates and carboxyphosphonates by use of 2,2'-bipyridine as auxilliary ligand: Structural variability and topological analysis. Cryst. Growth Des. 2013, 13, 4480-4489.

(54) Demadis, K. D.; Stavgianoudaki, N. Structural diversity in metal phosphonate frameworks: Impact on applications. In Metal phosphonate chemistry: From synthesis to applications; Clearfield, A., Demadis, K. D., Eds.; Royal Society of Chemistry: London, 2012; Chapter 14, pp 438-492.

(55) Fidelli, A. M.; Armakola, E.; Demadis, K. D.; Kessler, V. G.; Escuer, A.; Papaefstathiou, G. S. Cu(II) frameworks from di-2-pyridyl ketone and benzene-1,3,5-triphosphonic acid. Eur. J. Inorg. Chem. 2018, 2018, 91-98.

(56) Beevers, C. A.; Lipson, H. The crystal structure of copper sulfate pentahydrate $\mathrm{CuSO}_{4} \cdot 5 \mathrm{H}_{2}$ O. Proc. R. Soc. London, Ser. A 1934, $146,570-582$. 
(57) Infantes, L.; Motherwell, S. Water clusters in organic molecular crystals. CrystEngComm 2002, 4, 454-461.

(58) Kopylovich, M. N.; Tronova, E. A.; Haukka, M.; Kirillov, A. M.; Kukushkin, V.Yu.; Fraústo da Silva, J. J. R.; Pombeiro, A. J. L. Identification of hexameric water and hybrid water-chloride clusters intercalated in the crystal hosts of imidoylamidine nickel(II) complexes. Eur. J. Inorg. Chem. 2007, 2007, 4621-4627.

(59) Grancha, T.; Ferrando-Soria, J.; Cano, J.; Amorós, P.; Seoane, B.; Gascon, J.; Bazaga-García, M.; Losilla, E. R.; Cabeza, A.; Armentano, D.; Pardo, E. Insights into the Dynamics of Grotthuss Mechanism in a Proton-Conducting Chiral bioMOF. Chem. Mater. 2016, 28, 4608-4615.

(60) Colodrero, R. M. P.; Salcedo, I. R.; Bazaga-Garcia, M.; MillaPerez, D. F.; Duran-Martin, J. D.; Losilla, E. R.; Moreno-Real, L.; Rius, J.; Aranda, M. A. G.; Demadis, K. D.; Olivera-Pastor, P.; Cabeza, A. Pure Appl. Chem. 2017, 89, 75-87.

(61) Kreuer, K.-D. Proton conductivity: Materials and applications. Chem. Mater. 1996, 8, 610-641.

(62) Kreuer, K.-D.; Rabenau, A.; Weppner, W. Vehicle mechanism, a new model for the interpretation of the conductivity of fast proton conductors. Angew. Chem., Int. Ed. Engl. 1982, 21, 208-209.

(63) Shalini, S.; Aggarwal, S.; Singh, S. K.; Dutt, M.; Ajithkumar, T. G.; Vaidhyanathan, R. 10000-Fold enhancement in proton conduction by doping of cesium ions in a proton-conducting zwitterionic metal-organic framework. Eur. J. Inorg. Chem. 2016, 2016, 43824386.

(64) Shul'pin, G. B. New Trends in Oxidative Functionalization of Carbon-Hydrogen Bonds: A Review. Catalysts 2016, 6, 50.

(65) Olah, G. A.; Molnar, A. Hydrocarbon chemistry; Wiley: New York, 2003.

(66) Bäckvall, J.-E., Ed. Modern oxidation methods; Wiley: New York, 2011.

(67) Schuchardt, U.; Cardoso, D.; Sercheli, R.; Pereira, R.; da Cruz, R. S.; Guerreiro, M. C.; Mandelli, D.; Spinace, E. V.; Pires, E. L. Cyclohexane oxidation continues to be a challenge. Appl. Catal., A 2001, 211, 1-17.

(68) Dias, S. S. P.; Kirillova, M. V.; André, V.; Kłak, J.; Kirillov, A. M. New tricopper(II) cores self-assembled from aminoalcohol biobuffers and homophthalic acid: synthesis, structural and topological features, magnetic properties and mild catalytic oxidation of cyclic and linear C5-C8 alkanes. Inorg. Chem. Front. 2015, 2, 525-537.

(69) Gupta, S.; Kirillova, M. V.; Guedes da Silva, M. F. C.; Pombeiro, A. J. L.; Kirillov, A. M. Alkali metal directed assembly of heterometallic $\mathrm{V}^{\mathrm{v}} / \mathrm{M}(\mathrm{M}=\mathrm{Na}, \mathrm{K}, \mathrm{Cs})$ coordination polymers: Structures, topological analysis, and oxidation catalytic properties. Inorg. Chem. 2013, 52, 8601-8611.

(70) Kirillov, A. M.; Kirillova, M. V.; Pombeiro, A. J. L. Multicopper complexes and coordination polymers for mild oxidative functionalization of alkanes. Coord. Chem. Rev. 2012, 256, 2741-2759. 